\title{
Prevalence of Behavioral Health Conditions Across Frequency of Cannabis Use Among Adult Primary Care Patients in Washington State
}

\author{
Gwen T. Lapham, PhD, MPH MSW', , Amy K. Lee, MPH', Ryan M. Caldeiro, MD ${ }^{3}$, \\ Joseph E. Glass, PhD MSW', , David S. Carrell, $P h D^{7}$, Julie E. Richards, $M P H^{1,2}$, and \\ Katharine A. Bradley, MD, MPH $H^{1,2,5,6}$
}

\begin{abstract}
'Kaiser Permanente Washington Health Research Institute, Seattle, WA, USA; '²epartment of Health Services, University of Washington School of Public Health, Seattle, WA, USA; ${ }^{3}$ Kaiser Permanente Washington, Seattle, WA, USA; ${ }^{4}$ Department of Psychiatry and Behavioral Sciences, University of Washington School of Medicine, Seattle, WA, USA; ${ }^{5}$ Department of Veterans Affairs Puget Sound Health Care System, Health Services Research \& Development (HSR\&D) Denver-Seattle Center of Innovation for Veteran-Centered and Value-Driven Care, Seattle, WA, USA; '́School of Medicine, Department of Medicine, University of Washington, Seattle, WA, USA.
\end{abstract}

KEY WORDS: cannabis; primary care; screening; substance-related disorders; depression.

J Gen Intern Med 33(11):1833-5

DOI: $10.1007 / \mathrm{s} 11606-018-4558-8$

(c) Society of General Internal Medicine 2018

\section{INTRODUCTION}

Cannabis is the third most commonly used drug in the USA, after alcohol and tobacco, and the prevalence of cannabis use and cannabis use disorders (CUD) has doubled in the last decade, due in part to increasingly legalized access. ${ }^{1,2}$ Individuals who use cannabis have increased risk of behavioral health conditions, including depression, anxiety, and tobacco, alcohol, and other substance use disorders, ${ }^{3-5}$ but little is known about the association between frequency of cannabis use and behavioral health conditions among primary care patients. This population-based study of primary care patients ${ }^{6}$ reports on the prevalence of common behavioral health conditions across cannabis use frequency.

\section{METHODS}

Study details are described in a prior study of the prevalence of cannabis use in primary care. ${ }^{6}$ Briefly, Kaiser Permanente Washington, a large health system in Washington State where medical and nonmedical cannabis use is legal, implemented annual behavioral health screening, including a single-item about the frequency of past-year cannabis use, in three primary care sites beginning March 2015. Data are from electronic health record (EHR) and claims. Patients were included if they were $\geq$ 18 years old, had an in-person primary care visit before mid-February 2016, and completed screening (74\% of adults who visited).

Published online July 10, 2018
Cannabis frequency was categorized into three levels of past-year use - none, less than daily use, and daily use. Other behavioral health conditions identified by screening included depression symptoms (Patient Health Questionnaire-2 [PHQ2]; $\geq 2$ points on either item), unhealthy alcohol use (Alcohol Use Disorders Identification Test-Consumption [AUDIT-C]; $\geq 3$ points women; $\geq 4$ men), and any illicit drug use and/or medication misuse. ${ }^{6}$ Other conditions assessed in the year prior to the screen included EHR-documented tobacco use and composite indicators for both mental health and substance use disorder diagnoses derived from EHRdocumented International Classification of Disease 9/10 codes. $^{6}$

Sample characteristics, including the unadjusted prevalence of behavioral health conditions, were calculated. The age- and gender-adjusted prevalence of behavioral health conditions across three levels of cannabis use frequency was estimated from logistic regression models. ${ }^{6}$ Linear tests of trend assessed whether the frequency of cannabis use was associated with each condition, and separate interactions of cannabis use with age and gender were tested. Results are presented as the average adjusted probability, with $95 \%$ confidence intervals (CI), of each condition.

\section{RESULTS}

Table 1 summarizes the study sample $(n=22,095)$. Adjusted models indicated that behavioral health conditions were increasingly common with more frequent cannabis use (Fig. 1). Age-modified associations of cannabis use frequency with unhealthy alcohol use $(p=0.030)$ and tobacco use ( $p=0.019$ ) such that young adult patients (18-29 years) who used cannabis were at increased risk of both (data available upon request). Specifically, among young adult patients, the increased risk of unhealthy alcohol use was 
Table 1 Primary Care Adult Patients Who Responded to a Question About Past-Year Cannabis Use ( $n$ 22,095)

\begin{tabular}{|c|c|c|}
\hline & $N$ & $\%$ \\
\hline \multicolumn{3}{|l|}{ Gender } \\
\hline Women & 13,182 & (59.7) \\
\hline Men & 8913 & $(40.3)$ \\
\hline \multicolumn{3}{|l|}{ Age categories } \\
\hline $18-29$ & 2228 & (10.1) \\
\hline $30-49$ & 5194 & (23.5) \\
\hline$\geq 50$ & 14,673 & $(66.5)$ \\
\hline \multicolumn{3}{|l|}{ Race/ethnicity } \\
\hline Black & 490 & (2.2) \\
\hline Hispanic & 997 & (4.5) \\
\hline Other & 1972 & (8.9) \\
\hline White & 17,993 & (81.4) \\
\hline \multirow{2}{*}{\multicolumn{3}{|c|}{ Frequency of past-year cannabis use* }} \\
\hline & & \\
\hline None & 18,716 & (84.7) \\
\hline Less than daily & 2693 & (12.2) \\
\hline Daily & 686 & (3.1) \\
\hline \multicolumn{3}{|l|}{ Behavioral health conditions } \\
\hline Tobacco use (in the past year) ${ }^{\dagger}$ & 2133 & (9.7) \\
\hline $\begin{array}{l}\text { Any mental health diagnosis } \\
\text { (in the past year) }\end{array}$ & 5340 & $(24.2)$ \\
\hline $\begin{array}{l}\text { Any substance use disorder diagnosis } \\
\text { (in the past year) }^{\S}\end{array}$ & 635 & $(2.9)$ \\
\hline Depression symptoms (in the past 2 weeks)II & 3582 & (16.3) \\
\hline Unhealthy alcohol use (in the past year) ${ }^{\mathrm{II}}$ & 5863 & (26.6) \\
\hline $\begin{array}{l}\text { Illicit drug use and/or medication misuse } \\
\text { (in the past year)II }\end{array}$ & 363 & $(1.7)$ \\
\hline
\end{tabular}

*Based on single-item question: "How often in the past year have you used marijuana?" - none ("never"), less than daily ("less than monthly," "monthly," "weekly,"), and daily ("daily or almost daily"), where marijuana use could include nonmedical or medical use

${ }^{7}$ Assessed in the year prior to initial visit to pilot clinic

${ }^{*}$ Includes EHR-documented ICD 9/10 codes for major depressive disorders, anxiety disorders, and serious mental health disorder in the year prior to the cannabis screen

SIncludes EHR-documented ICD 9/10 codes for alcohol, cannabis, and all other drug use disorders (not including tobacco) in the year prior to the cannabis screen

"Behavioral health screens asked alongside the cannabis screen Total $N$ varies due to some patients not completing screen items: PHQ-2 (n 22,081); AUDIT-C for unhealthy alcohol use (n 22,034); drug screen (n 21,945); observed for those who reported any past-year cannabis use (52\% [95\% CI 49-56\%]), whereas the increased risk for tobacco use was observed among those who reported daily cannabis use (39\% [95\% CI 32-46\%]). No other age or gender interactions were significant.

\section{DISCUSSION}

Our study found a strong association between the frequency of cannabis use and tobacco use, depression symptoms, and other drug use, and as well as diagnosed mental health and substance use disorders. Tobacco and unhealthy alcohol use were most common among young adult patients who reported daily and any past-year cannabis use, respectively. Among patients who used cannabis daily, nearly $50 \%$ reported depression symptoms and more than $35 \%$ had a past-year mental health disorder diagnosis.

Despite limitations (e.g., cross-sectional design, single health system, mostly white sample), findings have important implications. Asking about the frequency of cannabis use as part of routine behavioral health screening in primary care, in a state with legalized use, identifies patients at increased risk for substance use and mental health conditions. Because cannabis use is associated with an increased risk of other substance use disorders, including tobacco and alcohol use disorders ${ }^{4}$ information about cannabis use should be integrated into recommended tobacco and alcohol counseling. In addition, patients with mental health conditions who use cannabis frequently can be engaged in discussions of how their use relates to their mental health symptoms. ${ }^{5}$ Integrating routine assessment of cannabis use into primary behavioral health care will become increasingly important to understand patients' needs as legalization expands.

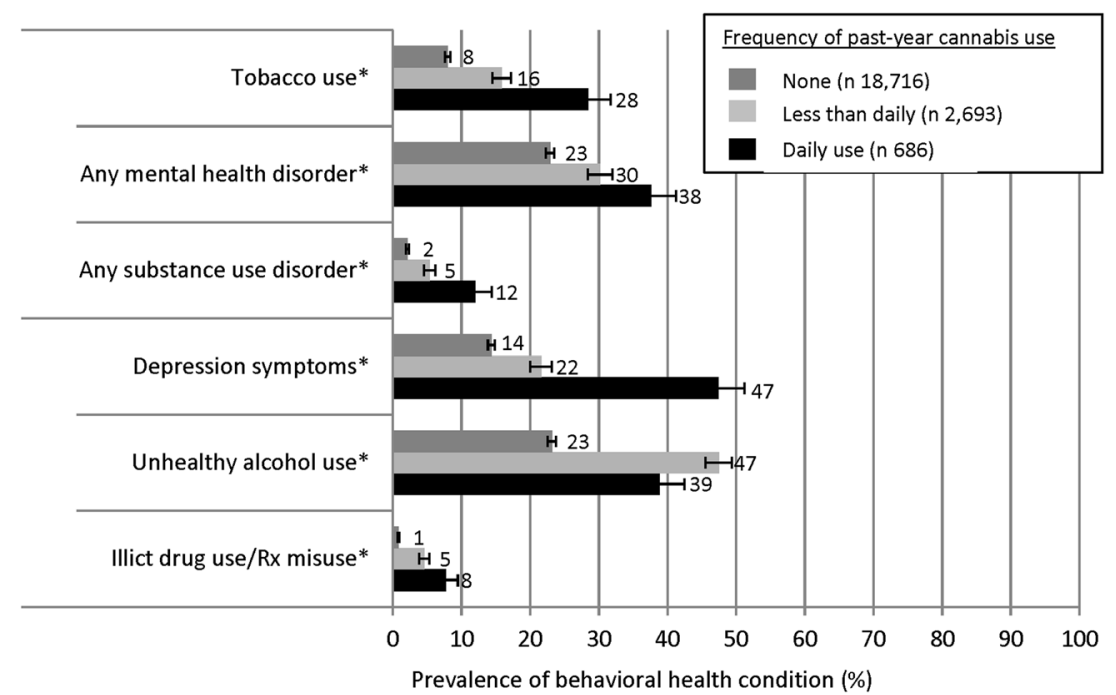

Figure 1 Age- and gender-adjusted prevalence of behavioral health conditions for each frequency of past-year cannabis use *Significant test of trend at $p<0.001$ for all conditions 
Corresponding Author: Gwen T. Lapham, PhD, MPH MSW; Kaiser Permanente Washington Health Research Institute, Seattle, WA, USA (e-mail: lapham.g@ghc.org).

Authors' Contributions Dr. Lapham had full access to all the study data and takes responsibility for the integrity of the data and the accuracy of the data analysis. Study concept and design: Lapham, Bradley. Statistical analysis: Lapham. Interpretation of results: All authors. Drafting of manuscript: Lapham, Bradley. Critical revision of the manuscript for important intellectual content: All authors.

Funding/Support Awards from the National Institute on Drug Abuse (UG1DA040314-01S1, UG1 DA01581; NIDA Clinical Trials Network Protocol \#0065-OT) and the Agency for Healthcare Research and Quality (R18 HSO23173) supported study implementation, analysis, and manuscript preparation. JEG was supported by the National Institute on Alcohol Abuse and Alcoholism (KO1AA023859). KAB was supported by K24 AA022128.

\section{Compliance with ethical standards:}

Conflict of Interest: The authors declare that they do not have a conflict of interest.

Role of the Sponsor: The sponsors had no role in the design and conduct of the study; collection, management, analysis, and interpretation of the data; preparation, review, or approval of the manuscript; and decision to submit the manuscript for publication.

\section{REFERENCES}

1. National Survey on Drug Use and Health. Key Substance Use and Mental Health Indicators in the United States: Results from the 2016 National Survey on Drug Use and Health. https://www.samhsa.gov/data/sites/ default/files/NSDUH-FFR1-2016/NSDUH-FFR1-2016.pdf. Accessed 29 May 2018.

2. Hasin DS, Kerridge BT, Saha TD, et al. Prevalence and Correlates of DSM-5 Cannabis Use Disorder, 2012-2013: Findings from the National Epidemiologic Survey on Alcohol and Related Conditions-III. Am J Psychiatry 2016;173(6):588-599.

3. Pacek LR, Martins SS, Crum RM. The bidirectional relationships between alcohol, cannabis, co-occurring alcohol and cannabis use disorders with major depressive disorder: results from a national sample. J Affect Disord 2013;148(2-3):188-195.

4. Blanco C, Hasin DS, Wall MM, et al. Cannabis Use and Risk of Psychiatric Disorders: Prospective Evidence From a US National Longitudinal Study. JAMA Psychiatry 2016;73(4):388-395.

5. Lev-Ran S, Roerecke M, Le Foll B, George TP, McKenzie K, Rehm J. The association between cannabis use and depression: a systematic review and meta-analysis of longitudinal studies. Psychol Med 2014;44(4):797810.

6. Lapham GT, Lee AK, Caldeiro RM, et al. Frequency of Cannabis Use Among Primary Care Patients in Washington State. J Am Board Fam Med 2017;30(6):795-805. 